\title{
“NATURALEZAS" EN DEBATE. SENTIDOS, APROPIACIONES Y DISCUSIONES EN TORNO AL ESPACIO Y TERRITORIO
}

\author{
Artur H. Franco Barcelos* y Carlos D. Paz**
}

Recibido: 25/09/2016 //Aceptado: 10/12/2016

En el marco de las XVI Jornadas Internacionales sobre Misiones Jesuiticas, cuyo lema era 'Iberoamérica: Espacios misionales en diálogo con la globalidad', se presentó, una vez más, el Simposio Temático Territorio, espacio y poblaciones en el marco de las misiones jesuíticas americanas, coordinado por Artur H. Franco Barcelos (FURG / Brasil) y Carlos D. Paz (FCH-UNCPBA / Argentina).

El Simposio se constituyó, al igual que en ediciones anteriores de las Jornadas, como un lugar de puesta en común y debate de investigaciones en curso, con distintos grados de avance, que dieran cuenta de los modos en que el accionar misional jesuítico, en su control sobre los cuerpos y los espacios en dónde se producían las relaciones entre los nativos, ocasionó transformaciones, adaptaciones de uso y significación así como nuevas formas indias de concebir el espacio y el territorio. La primera de las categorías, tal como expusimos en la formulación de nuestro Simposio, atiende a aquellas performances que dan sentido y sustentan a una comunidad que se reproduce material, e inmaterialmente, en una porción de territorio, continuo o discontinuo, que permite identificar a cada una de las comunidades que abordamos por medio de nuestras investigaciones. El territorio, por su parte, es la porción física, también construida y modificada socialmente, en dónde se sustentan aquellas prácticas generadoras de sentido. De este modo, territorio y espacio, se comportan como una distinción operativa para indagar en las formas de relación de las poblaciones amerindias tanto entre sí como con los recién llegados.

Los tres trabajos que aquí comentamos representan un logrado balance entre avances de investigación así como con resultados empíricamente contrastables por demás promisorios ya modo de punto de partida para nuevas indagaciones sobre el espacio como un problema que requiere de atención constante. Un aspecto que necesita, imperiosamente, de abordajes recurrentes, pero no redundantes, para poder complejizar nuestro conocimiento sobre las formas nativas, aunque no exclusivamente indígenas, de relación con el espacio y los sujetos con los cuales se trabaron relaciones sociales; las cuáles permiten brindar historicidad al territorio como un todo articulado.

* Doctor en Historia. FURG / Brasil. ahbarcelos@hotmail.com

** Doctor en Historia. FCH-UNCPBA/Argentina. paz_carlos@yahoo.com 
María del Rosario Soto Lescale (Universidad Pedagógica Nacional / México) presenta un trabajo por demás sugerente; “¿Respeto o debilidad? Los Jesuitas en la Tarahumara". Allí, desde una indagación que conjuga una notable descripción del espacio así como un rastreo propio de la Historia del Arte, se expone en qué modo el templo de Santa María de las Cuevas significa mucho más que el lugar desde dónde la evangelización se pregonó entre los tarahumaras. Los nativos se apropiaron de aquel espacio de un modo sutil; sublime; estratégico. Todo ello como parte de un proceso en dónde los conversores confiaban algunas tareas a los nativos. De este modo y con relación a aquel templo, la pintura de los muros les fue encomendada como parte de su condición gentil y en aras de inculcarle hábitos que fueran, entre tantos otros, un pilar para su evangelización. En ese contexto, y como provocación excelsa, Soto Lescale señala un dato preciso para comprender tanto aquel proceso así como para abrir el debate sobre las formas de producción social del espacio.

Las paredes de Santa María de la Cuevas fueron transformadas en un marcador sociológico de una identidad tarahumara; “...las flores [pintadas en] los muros resultan casi infantiles, siendo un dibujo simplificado de la misma flor de cholla, del mismo color, rojo (color del sol). ¿Por qué no pintar flores de múltiples colores, siendo ya el barroco mexicano? ¿Por qué usar un sólo motivo que representa al dios Sol de la gentilidad?" (Soto Lescale; pp. 14-15, de manuscrito)

Esta pregunta es un disparador de múltiples cuestiones que colocan en debate desde dónde es que podemos analizar la conformación del espacio y cómo el mismo permite a los sujetos identificarse como partícipes de un conjunto que se reconoce como una unidad y, en un contexto de relaciones sociales atravesadas por nuevas relaciones de poder, reconformar su identidad dando paso, sin lugar a dudas, a nuevas formas de poder así como de representación del mismo. "De esta manera, mientras los jesuitas pensaban que los tarahumaras visitaban la iglesia por ser la casa del dios católico, quizá ellos iban a ver los símbolos de sus dioses primigenios" (Soto Lescale; pp. 15, del manuscrito), pero ahora insertos en una trama social distinta. Dioses, hombres, entidades naturales -no-humanas desde una concepción ontológica- e instituciones se amalgamaron en los espacios de reducción y, especialmente, en sus templos. Sin lugar a dudas una cuestión que no es para novedosa aunque sí el modo de analizarlo.

Esta relación con el medio ambiente, que en sí misma es un modo de relación social, fue fundamental para la supervivencia y reproducción, material e inmaterial, de una forma de ser. Aspectos mínimos de una vida cotidiana que pasaron desapercibidos por algún tiempo para los investigadores pero que se encontraban traslapados en el cuerpo documental. La referencia a prácticas de sentido cotidianas de los nativos se encuentra ampliamente documentada en los testimonios jesuíticos pero, en más de una ocasión, los prejuicios ideológicos de los mismos hicieron que concepciones sobre el espacio que se hallan presentes en esas prácticas de la vida cotidiana fueran pasadas por alto o bien sólo retomadas con relación a problemas como por ejemplo guerras cuyo fundamento, desde la óptica ignaciana, eran por el control de determinados territorios. 
Desde una perspectiva jesuítica este tipo de conflictos tenían lugar por el acceso de campos de pastoreo de ganados o pescaderos que brindaban cierta protección contra potenciales enemigos a la vez que recursos. Lo que se oculta desde el prisma jesuítico son los sentidos que podríamos denominar, de modo reduccionista por cierto, mágico-religiosos de y sobre el espacio tanto terrestre como cósmico. No podemos olvidar que en más de una narrativa ignaciana aparecen menciones a cómo es que los indígenas cuestionaban el lugar dónde se emplazaban las reducciones debido a ataques de sus enemigos o bien a lo insalubre del entorno, ya fuera por condiciones mismas del emplazamiento o bien por no disponer de recursos necesarios para la vida comunal.

Para poder brindar mejores explicaciones sobre las formas sobre el ser indígena y su vínculo estrecho y fundante del ser con el medio ambiente, es necesario disponer de estudios profundos sobre la lengua y cómo la misma expresa nociones sobre el espacio, al mismo tiempo que ésta alberga saberes sobre cómo desplazarse por el mismo. Movimiento estacional, de intensidad y ritmo variable, que hacía y hace posible aún la articulación de distintos grupos familiares que se reconocen como parte de una misma nación.

En el caso de los guarani la investigación de Angélica Otazú (Universidad Católica "Nuestra Señora de la Asunción" - CONACYT / Paraguay) "Los guarani y su orientación en el espacio" trae al debate un problema de notable importancia aunque pocas veces tratado por la historiografía; aun por la especializada. Moverse por el terreno requiere de un conocimiento del mismo, a la vez que orientación y un bagaje de conocimientos que pueden capitalizarse en función de las distintas necesidades sociales que enfrenta la comunidad en determinado momento. La búsqueda de comida; los movimientos de exploración y repliegue ante la posibilidad de enemigos; disponer de medicinas para el cuerpo y el alma o bien caminar por el 'monte' requiere de un saber propio de una comunidad que necesita ser develado si es que apuntamos a profundizar lo que conocemos sobre las formas de organización social de los nativos así como sus transformaciones durante la etapa colonial al mismo que tiempo qué, a partir de abordajes como los de Otazú, podemos proponer nuevas formas de pensar la relación medio-hombre que sustenta aquella 'ecología de los otros'.

Angélica Otazú, desde una sensibilidad profunda, alimentada por estadías de trabajo de campo en las que precisamente indagaba sobre la lengua guaraní como un todo; como un ser; una forma de ser en el mundo, pone el dedo en el renglón sobre un aspecto que merece atención así como una toma de posición clara. Los guaraní actuales, base de muchas investigaciones antropológicas sobre los guaraní históricos, están siendo matados, sobre todo en el SE de Brasil, por la expansión del agronegocio de monocultivo. Allí dónde los guaraní no son muertos, como una expresión "más humanitaria" -aunque de un cinismo absoluto-, son expulsados de sus tierras y obligados a vivir, literalmente, en los márgenes no ya de la sociedad si no de la humanidad misma. Los desplazados son forzados a lograr sustentarse en entornos dónde ya no disponen no sólo de sus tierras si no que, en muchos casos, la mendicidad pasó a ser, tristemente, su forma de vida. 
Barcelos y Paz. "Naturalezas" en debate. Sentidos, apropiaciones y discusiones en torno al espacio y al territorio.

La lengua, como una expresión de aquel ser-guarani, el tan nombrado tekoha, tanto entre los guarani como en otros grupos étnicos de América toda, se encuentra viva y, mutatis mutandis, nos hace llegar formas de pensar en cómo se producen, y cómo se formularon, esos procesos de cambio ante situaciones que se presentan como traumáticas. Otazú, como vocera de muchas comunidades, señala: "Es precisamente en la sabiduría de sus antepasados que encuentran el sentido de su lucha. Es evidente, que la cultura no desaparece mientras haya un pueblo que la promueve y busca nuevos caminos para innovar las prácticas tradicionales" (Otazú, pp. 7 del manuscrito). Saberes comunales que aún persisten por más que muchas veces los guaraní no deseen hablar de ellos como un resultado más del saqueo al que han sido expuestos. Dentro de estas expresiones es dónde hallamos referencias a cómo y por dónde desplazarse; la dinámica del viento; su conocimiento sobre las constelaciones y la incidencia de las mismas sobre la vida terrenal; etc. Estos aspectos pueden ser la guía para una nueva lectura de un cuerpo documental que en más de una ocasión amenaza con agotarse en aportaciones notorias sobre las formas de vida nativas durante la etapa colonial.

Dentro del registro documental de las acciones nativas y, como una forma de componer una explicación sobre las disputas por el territorio y confrontar espacialidades, como en el caso de aquellos nativos reducidos y grupos que no aceptaron tal política, se hace presente, desde los dispositivos de poder coloniales, constantes menciones sobre las guerras indias y cómo es que las mismas se incrementaron luego de la conformación de pueblos de misión. Un caso bajo análisis es el que Diego Bracco (Centro Universitario de Tacuarembó. UdelaR / Uruguay) titula "Charrúas, bohanes, pampas y guenoa minuanos en los pueblos de misiones".

Bracco no sólo presenta el contexto de guerra que marcó el comienzo del siglo XVIII en la conocida Banda Oriental sino que a partir de un abordaje documentado minuciosamente hace posible afinar aún más nuestro conocimiento de la conformación de aquellas etiquetas étnicas desde las cuáles conocemos a los distintos grupos nativos; los mismos que con su política de alianzas y afinidades negativas ayudaron a moldear toda una imagen de aquel territorio así como de cada uno de ellos.

Cada uno de aquellos rótulos étnicos encubren una amplia gama de uniones parentales qué son las que hacen posible desentrañar, ponderando las intencionalidades y ambiciones personales de cada líder de grupo político, secundado por su base social de poder, los vaivenes de la política y cómo es que la misma se puede traducir por medio de una sociología de la guerra que formule proposiciones desde la larga duración de los ciclos de enfrentamientos armados. Aunque, en rigor de verdad y para ahondar en dicha sociología deberíamos de ponderar la relación de los nativos con su entorno, tanto humano y no-humano, desde proposiciones cercanas a las de Soto Lescale y aquellas de Otazú para así dar cuenta de cómo es que las alteraciones producidas en la territorialidad nativa generaron cambios con los 'dueños del monte'; relación que presentada y analizada en conjunto con los ciclos de guerra y con las referencias a la presencia en las mismas de líderes cumpliendo funciones religiosas puede significar avances notables en el conocimiento de las relaciones de afinidad nativas y cómo es que las mismas se visibilizan tanto por medio de la espacialidad como en la territorialidad. 
La fidelidad al cristianismo y su relación tanto con el acceso a la propiedad de la tierra así como su incidencia en la justificación de la guerra, así como en otras prácticas sociales que brindaban cohesión social y que eran presentadas como vicios morales por los jesuitas, se hace presente como Deus ex machina de una serie de acciones jesuitas, y reacciones nativas, en el proceso de conversión. Proceso dónde la puja principal siempre aparece vinculada a la tierra tal como lo sostiene Bracco.

Las investigaciones que aquí presentamos dialogan con aquellas otras, parte del mismo Simposio Temático al que hicimos referencia al comienzo de esta presentación, al que el lector interesado podrá acceder desde http://www.iighi-conicet.gob.ar/wpcontent/uploads/2016/12/Libro-de-Actas-Digitales.pdf. En su conjunto brindan al lector un marco de referencia, variado, sobre un abanico de realidades sociales a las que abordamos desde el accionar misional reduccional llevado a cabo por la Compañía de Jesús a lo largo de su experiencia colonial americana.

Sin lugar a dudas los problemas que enumeramos aquí no agotan, ni mucho menos, la problemática que concierne al territorio y al espacio. Claro, todo se sucede en un territorio y la espacialidad no es más que un diacrítico que separa, o une, grupos sociales, e individuos, en función de intereses propios de una temporalidad y una concepción sobre la misma que aún requiere de abordajes con mayor grado de sistematicidad. Reclamo que se funda en que todos los grupos humanos poseen formas propias -si es que la autoridad sobre la misma puede reclamarse sin ponderar los contínuos procesos de diálogos con formas de alteridad no excluyentes- de percibir, identificar y justificar el cambio.

Toda aquella documentación con la que abordamos la relación de los nativos con su entorno propone una visión inmovilista de la realidad indígena. Sin embargo los resultados de investigación arrojan resultados a la misma vez que proponen formulaciones originales que dan cuenta de una capacidad creativa notable. Producto quizás de aquel diálogo constante, y previo a la conquista, con formas de alteridad no excluyentes. Parafraseando a Clastres, el problema de los grupos indios radica en no tener con quién establecer relaciones políticas; concibiendo a la política, y no sólo a la terrenal y entre humanos, de un modo por demás amplio y complejo.

La Compañía de Jesús, desde sus bases intelectuales, proponía una forma de administración de la relación entre los hombres, con sus cuerpos y el espacio que los albergaba, disímil, y por momentos antagónica, con aquella propia del mundo indígena americano. Sin embargo, y en determinadas ocasiones, al menos hasta el período republicano cuando los aparatos de control mostraron una mayor capacidad punitiva, los nativos encontraron formas de escapar al control que se proponía sobre su sí-mismo. Son aquellas formas las que encontramos en los archivos y qué, en esta oportunidad, exponen nuestros colegas. Mucho más recientemente la voz nativa surge en narrativas formuladas por ellos mismos y bajo cánones que dan cuenta de su lógica argumental; ya no de cómo nosotros concebimos la Historia. Allí es donde debemos de mirar dejando de lado posturas fisgonas o bien que pretendan la mera 'traducción'/'domesticación' de aquellas lógicas. Del mismo modo en que los jesuitas para misionalizar en China 
Barcelos y Paz. "Naturalezas" en debate. Sentidos, apropiaciones y discusiones en torno al espacio y al territorio.

debieron volverse 'chinos', como investigadores de la realidad nativa americana preocupados por sus prácticas sociales, debemos de estar atentos a las epistemologías indias que subyacen en la documentación preparada con fines específicos durante la etapa colonial. Indagar desde esa premisa, sin lugar a dudas, reportará nuevas preguntas a una temática prolífica y promisoria. 